Journal of Current and Advance Medical Research

July 2021, Vol. 8, No. 2, pp. 119-124

http://www.banglajol.info/index.php/JCAMR ISSN

(Print) 2313-447X

ISSN (Online) 2413-323X

NLM Catalog ID 101673828

DOI: https://doi.org/ 10.3329/jcamr.v8i2.57437

ORIGINAL ARTICLE

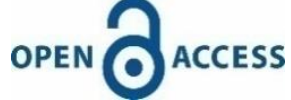

\title{
Post-Operative Complications after Thyroid Gland Surgery due to Different Pathologic Condition: A Prospective Study
}

\author{
Rana Jahangir Alam ${ }^{1}$, Mohammad Salim², Sayem Al Monsur Faizi ${ }^{3}$, Aklima Parvin ${ }^{4}$, Farah Naz \\ Amina $^{5}$, Bidyut Chandra Debnath ${ }^{6}$, Ibrahim Siddique ${ }^{7}$
}

\begin{abstract}
${ }^{1}$ Medical Officer, Department of Surgery, Bangabandhu Sheikh Mujib Medical University, Dhaka, Bangladesh; ${ }^{2}$ Medical Officer, Department of Surgery, Bangabandhu Sheikh Mujib Medical University, Dhaka, Bangladesh; ${ }^{3}$ Medical Officer, Department of Surgery, Bangabandhu Sheikh Mujib Medical University, Dhaka, Bangladesh; ${ }^{4}$ Assistant Registrar, Department of Surgery, Sarkari Karmochari Hospital, Dhaka, Bangladesh; ${ }^{5}$ Medical Officer, Department of Medicine, Shaheed Ziaur Rahman Medical College Hospital, Dhaka, Bangladesh; ${ }^{6}$ Associate Professor, Department of Surgery, Bangabandhu Sheikh Mujib Medical University, Dhaka, Bangladesh; ${ }^{7}$ Professor, Department of Surgery, Bangabandhu Sheikh Mujib Medical University, Dhaka, Bangladesh
\end{abstract}

[Received on: 11 April 2021; Accepted on: 2 My 2021; Published on: 1 July 2021]

\section{Abstract}

Background: The outcome and complication rates of post-operative cases are largely dependent on different factors. Objective: The objective of this study was to determine the risk factors responsible for major postoperative complications after thyroid surgery. Methodology: This was a prospective cohort study which was carried out at the Department of Surgery, Bangabandhu Shiekh Mujib Medical University, Dhaka, Bangladesh. Adult patients undergoing elective surgery for various thyroid disorders were selected as study population. This study was carried out from March 2009 to June 2011 for a period of two years. The study was included patients of various thyroid disorders that required surgical intervention of different magnitude. They were evaluated by history, physical examination, biochemical tests, ultrasound scan and FNAC where indicated. Histopathology was done and patients were followed up for subsequent outcome. Results: Among 2(2\%) of them developed reactionary haemorrhage. The most common immediate surgical complication following thyroidectomy is hypocalcaemia and 12 patients $(12 \%)$ experiencing this problem. $11(11 \%)$ patients developed transient tetany (hypocalcaemia) on 2nd post-operative day which was improved later on and $1(1 \%)$ patient developed permanent hypoparathyroidism and the patient supplemented by vitamin-D more than 6 months follow-up . In this study the mortality rate is $0 \%$ and complication rate is acceptable in comparison to other study. Conclusion: Hypoparathyroidism is a relatively common complication after thyroid surgery. [Journal of Current and Advance Medical Research, July 2021;8(2):119-124]

Keywords: Post-operative complications; thyroid gland; surgery

Correspondence: Dr. Rana Jahangir Alam, Medical Officer, Department of Surgery, Bangabandhu Sheikh Mujib Medical University, Dhaka, Bangladesh; Email: abcde04rana@ gmail.com; Cell no.: +880914499449

Cite this article as: Alam RJ, Salim M, Faizi SAM, Parvin A, Amina FN, Debnath BC, Siddique I. Post-Operative Complications after Thyroid Gland Surgery due to Different Pathologic Condition: A Prospective Study. J Curr Adv Med Res 2021;8(2):119-124 Funding: This study has been performed without any funding from outside else.

Conflict of Interest: There was no conflict of interest to any of the authors.

Contributions to authors: Alam RJ, Salim M, Faizi SAM had involved in the protocol preparation, data collection, statistical analysis as well as the report writing. Parvin A, Amina FN, Debnath BC, Siddique I involved in the manuscript preparation as well as manuscript correction. All authors were responsible for the research works.

Copyright: (O2021. Alam et al. Published by Journal of Current and Advance Medical Research. This article is published under the Creative Commons CC BY-NC License (https://creativecommons.org/licenses/by-nc/4.0/). This license permits use, distribution and reproduction in any medium, provided the original work is properly cited, and is not used for commercial purposes. 


\section{Introduction}

Thyroidectomy is a very common surgical procedure worldwide and is performed by the surgeons with variable training and backgrounds such as general surgery, thoracic surgery, endocrine surgery, otorhinolaryngology, oncological surgery, and head and neck surgery ${ }^{1}$. Thyroid surgery has followed all the steps of evolution to reach the time of endoscopic surgery. Endoscopic thyroid surgery is also reported from Bangladesh ${ }^{2}$. Thyroid surgery is one of the most frequently performed surgical procedures worldwide ${ }^{3}$.

Repeat thyroid surgery should be avoided if at all possible because it carries a much greater risk of injury to the parathyroid and RL nerve than primary thyroid surgery ${ }^{4}$. Sometimes a more disappointing situation arises after subtotal thyroidectomy for multinodular goitre that is the pressure symptoms persists after the operation. This is because of a strategically placed residual nodule usually in the retro-oesophageal or retro-tracheal site $^{5}$. This issue may be an argument for total thyroidectomy when there are associated pressure symptoms in multinodular goitre ${ }^{6}$. The present study focused on the major complications of thyroidectomy procedures amongst the patients with thyroid disorder. Commonly performed thyroid surgeries are total thyroidectomy, near total thyroidectomy, subtotal thyroidectomy, total thyroidectomy with functional neck dissection, completion thyroidectomy and hemithyroidectomy ${ }^{7}$.

Though thyroidectomy rarely is associated with mortality but many life threatening complications are not infrequent. Unless the surgeon is well trained and has adequate knowledge about the anatomy and pathologic basis of thyroid disorders, excellent results cannot be achieved ${ }^{8}$. Failure to follow the cardinal surgical principles may result in morbidity in a significant number of patients which could have been avoided ${ }^{9}$.

For proper thyroid surgery it needs to have complete support from the anesthiologist and also do need to have continuous monitoring of the patient pre operatively and port operatively ${ }^{10}$. In a tertiary level hospital like Bangabandhu Sheikh Mujib Medical University the facilities are available, that theaters are well equipped provision for operation. Post-operative care both the recovery room and also in ICU when there is need. But in district hospitals which are responsible for offering service to the most of the population all this services are not available; indeed it does not exist in most of the district hospital in Bangladesh. Therefore it is difficult to perform thyroid surgery with same standard in district level hospitals where expertise, experience and skills for thyroid surgery are not adequate. The objective of this study was to determine the risk factors responsible for major postoperative complications after thyroid surgery.

\section{Methodology}

This was a prospective cohort study. Adult patients undergoing elective surgery for various thyroid disorders were selected as study population. This study was carried out from March 2009 to June 2011 for a period of two years. This study was carried out at the Department of Surgery, Bangabandhu Shiekh Mujib Medical University, Dhaka. All adult patients ( $>18$ years) were selected irrespective of sex and present clinically with thyroid disorders where surgery was indicated. Detailed histories of each of the patients were recorded emphasizing every aspects of presenting features, diagnostic criteria and management of cases and subsequent follow up. Pediatric patients, puberty goiter or asymptomatic multinodular goiter with severe co morbid diseases like IHD, neuropathy, and peripheral vascular disease were excluded from this study. Convenient sampling technique was applied. Every consecutive patient was fulfilled the inclusion criteria were included in the study. The study was included more than 100 patients of various thyroid disorders that required surgical intervention of different magnitude. They were evaluated by history, physical examination, biochemical tests, ultrasound scan and FNAC where indicated. Histopathology was done and patients were followed up for subsequent outcome. Patient's information was obtained by using predefined patients information sheet, which comprises structured questionnaire pre-operative and postoperative observation and follow up of the patients. Data were processed, edited and analyzed. Findings of the study were compiled and calculated quantitative data were described accordingly and some qualitative data were coded and analyzed. Ethical clearance was taken from the local ethics review committee.

\section{Results}

A total number of 100 patients were recruited for this study. In this study age ranged was from 18 to 80 years. Most of the patients were in between 31 to 40 years $(38 \%)$ and the maximum incidence in 3rd and 4th decade (Table 1). 
Table 1: Age distribution among Study Population $(\mathbf{n}=100)$

\begin{tabular}{|l|c|c|}
\hline Age Group & Frequency & Percent \\
\hline 18 to 30 Years & 32 & 32.0 \\
\hline 30 to 50 Years & 50 & 50.0 \\
\hline 50 to 70 Years & 16 & 16.0 \\
\hline More Than 70 Years & 2 & 2.0 \\
\hline Total & $\mathbf{1 0 0}$ & $\mathbf{1 0 0 . 0}$ \\
\hline
\end{tabular}

Types of thyroid diseases where surgical interventions were carried out were simple multinodular goiter $(46 \%)$, papillary carcinoma $(32.0 \%)$, follicular carcinoma $(4.0 \%)$, medullary carcinoma (2.0\%), thyroiditis $(8.0 \%)$, nodular goiter and adenoma $(8.0 \%)$ which were confirmed by histopathological examination (Table 2).
Table 2: Types of Thyroid Diseases among the Study Population

\begin{tabular}{|l|c|c|}
\hline Thyroid Diseases & Frequency & Percent \\
\hline $\begin{array}{l}\text { Simple multi-nodular } \\
\text { goiter }\end{array}$ & 46 & 46.0 \\
\hline Papillary carcinoma & 32 & 32.0 \\
\hline Follicular carcinoma & 4 & 4.0 \\
\hline Medullary carcinoma & 2 & 2.0 \\
\hline Thyroiditis & 8 & 8.0 \\
\hline Nodular goiter \& Adenoma & 8 & 8.0 \\
\hline Total & $\mathbf{1 0 0}$ & $\mathbf{1 0 0 . 0}$ \\
\hline
\end{tabular}

The different types of thyroidectomy were performed in this study. Majority of the operations were total thyroidectomy and near total thyroidectomy respectively (Table 3 ).

Table 3: Diagnosis and Types of Operation $(n=100)$

\begin{tabular}{|l|c|c|c|c|}
\hline Name of Operations & $\begin{array}{c}\text { Simple } \\
\text { multinodular } \\
\text { goiter }(\mathrm{n}=46)\end{array}$ & $\begin{array}{c}\text { Carcinoma } \\
\text { of thyroid } \\
(\mathrm{n}=38)\end{array}$ & $\begin{array}{c}\text { Thyroiditis } \\
(\mathrm{n}=8)\end{array}$ & $\begin{array}{c}\text { Nodular goitre \& } \\
\text { Adenoma (n=8) }\end{array}$ \\
\hline Hemithyroidectomy & 2 & 2 & 4 & 4 \\
\hline Subtotal Thyroidectomy & 8 & 0 & 2 & 0 \\
\hline Near total Thyroidectomy & 12 & 4 & & 2 \\
\hline Total Thyroidectomy & 24 & 18 & 0 & 2 \\
\hline $\begin{array}{l}\text { Total Thyroidectomy with Functional } \\
\text { Neck Dissection }\end{array}$ & 0 & 8 & 0 & 0 \\
\hline Completion Thyroidectomy & 0 & 6 & 0 & 0 \\
\hline
\end{tabular}

Table 4: Major postoperative complications in relation to the type of surgery $(n=100)$

\begin{tabular}{|c|c|c|c|c|c|c|}
\hline \multirow[t]{2}{*}{ Postoperative Complications } & \multicolumn{6}{|c|}{ Operative Procedure } \\
\hline & 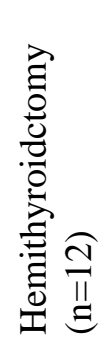 & 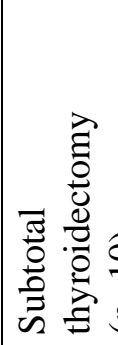 & 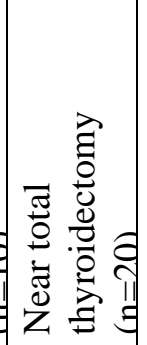 & 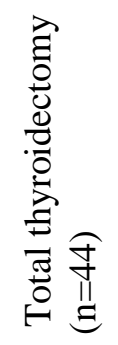 & 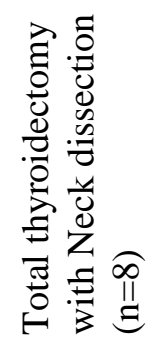 & 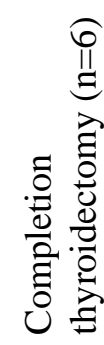 \\
\hline Reactionary haemorrhage & - & 1 & - & - & 1 & - \\
\hline Temporary vocal cord palsy (RLN Injury) & - & 1 & - & - & 1 & - \\
\hline Permanent Vocal cord palsy (RLN Injury) & - & - & - & - & - & - \\
\hline Temporary parathyroid insufficiency & 1 & 1 & 3 & 4 & 2 & - \\
\hline Permanent parathyroid insufficiency & - & - & - & - & - & 1 \\
\hline
\end{tabular}

Pie diagram had shown the major complications of thyroidectomy. Out of 100 cases 2 patients developed post-operative haemorrhage, 12 patients developed hypoparathyroidism and 2 patients developed recurrent laryngeal nerve injury (Figure I).
Among 100 patients incidence of temporary hypoparathyroidism was more and permanent vocal cord palsy was nil and in unilateral procedure complication rate was low (Table 4). 


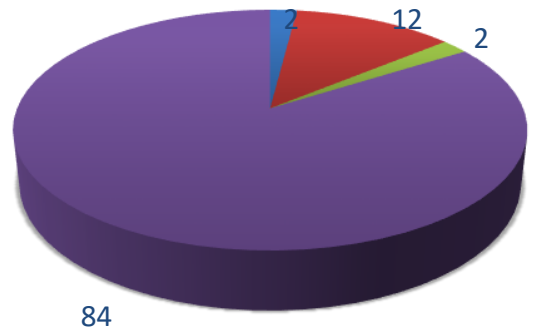

- Post-operative haemorrhage

- Hypoparathyroidism

Recurrent laryngeal nerve injury

\section{Figure I: Major Complications of thyroidectomy} $(\mathbf{n}=100)$

\section{Discussion}

In this study 100 patients were included who underwent surgical treatment for various thyroid disorders in the department of surgery of BSMMU, Dhaka from March 2009 to June 2011. The diagnoses of all these cases were established preoperatively by various thyroid function tests and later confirmed by histological examinations. Age of the patient ranged from 18 to 80 years and the maximum incidence in 3rd and 4th decade. Khanzada et $\mathrm{al}^{4}$ in their study found the maximum incidence in 3rd decade which result is more or less similar to this study.

In this series most of patients presented with simple multinodular goitre and carcinoma of thyroid with or without metastasis which were confirmed by histopathological examination. Out of 100 cases majority of the operations were total thyroidectomy $(44.0 \%)$ and near total thyroidectomy $(20.0 \%)$ respectively. In simple multinodular goitre total thyroidectomy were done in 24 cases to prevent recurrence, toxicity, malignancy and reduce risk of reoperation. In this study for malignant diseases total thyroidectomy, total thyroidectomy with neck dissection and completion thyroidectomy were done in 18,8 and 6 cases respectively. Despite the higher morbidity, total thyroidectomy is emerging as an attractive surgical option even for benign thyroid disease due to the risk of sub clinical (occult) malignancy, the possibility of goiter relapse as well as of the increased risk of complications following reoperation ${ }^{11-12}$.

Among 100 patients 16 patients developed postoperative complications where the incidence of parathyroid insufficiency were high (11.0\%), which were more common in bilateral procedures and carcinoma thyroid in this study. Chow et $\mathrm{al}^{11}$ in there study found parathyroid insufficiency approximate $30.0 \%$. Hypoparathyroidism, however, is a relatively common complication after surgery for thyroid cancer.

Out of 100 cases 16 patients developed postoperative complications, 2 of these patients developed post-operative haematoma. Both of them were subjected to bilateral procedure. In this study drains were kept deep to strap muscles in all bilateral procedures and selected unilateral procedures. Wound exploration revealed oozing from thyroid remnant in one patient and another one from middle thyroid vein due to diathermy at the time of surgery and not ligated. A haematoma deep to the cervical fascia is usually due to reactionary haemorrhage from one of the thyroid arteries; occasionally, haemorrhage from a thyroid remnant or a thyroid vein may be responsible. This is a rare but desperate emergency requiring urgent decompression by opening the layers of the wound, not simply the skin closure, to relieve tension before urgent transfer to theatre to secure the bleeding vessel ${ }^{9}$. There is no definite evidence that drains prevent haematoma or seroma formation and controversy still remains regarding the use of drains after thyroid surgery. It has also been reported that patients with drains had longer postoperative hospital stay and longer duration of postoperative pain. Similar result was experienced by Debry and colleagues $^{13}$. Drain should not be a substitute for intra-operative haemostasis. In the study of Karamanakos et $\mathrm{al}^{10}$ in Greece they found that postoperative haematoma occurred in $27(1.3 \%)$ patients out of 2043 patients. In all but one case, a drain was placed.

Haemorrhage into the thyroid bed following thyroidectomy is a life threatening condition. Accumulation of blood within the visceral compartment of neck results in tracheal compression laryngeal oedema and respiratory distress. Respiratory distress from a wound haematoma should be managed, if necessary cut the neck stitch at bed side and haematoma should be evacuated by reoperation. During operation, haemorrhage can be avoided by positioning the patient with the neck hyper extended and the head of the operating table elevated at $30^{\circ}$. This position provides excellent exposure and reduces cervical venous pressure. Substantial blood vessels in the operative field should be tied with fine vicril ligature. Whereas small vessels can be managed with the bipolar diathermy ${ }^{14}$. Methylcellulose (surgical) can also be used effectively to manage 
bleeding from the cut surface of the thyroid gland. Most surgeons favor the use of a small caliber closed suction drain for the 1 st 24 hours to remove blood and serum from operative bed.

In this series 11 patients developed post-operative transient hypoparathyroidism and 1 patient developed permanent hypoparathyroidism. Transient parathyroid insufficiency patients were recovering within 3 weeks to 6 months. Permanent hypoparathyroidism was defined as hypocalcaemia symptoms plus a requirement for oral vitamin $D$ and calcium 6 months after thyroidectomy ${ }^{15}$. In another study, hypoparathyroidism, defined functionally on the basis of requirement of calcium supplementation 1 year after surgery. Majid and Siddique $^{9}$ in their study found 52 patients $(8.69 \%)$ developed parathyroid insufficiency, among 51 patients (8.52\%) developed transient hypoparathyroidism and $(0.16 \%)$ developed permanent hypoparathyroidism. Karamanakos et $\mathrm{al}^{10}$ in his study found the rates of transient and permanent hypoparathyroidism were $27.8 \%$ and $4.8 \%$ respectively. Incidence of parathyroid insufficiency was higher in bilateral procedures in comparison to unilateral ones in this series. The most common immediate surgical complication following total thyroidectomy is hypocalcaemia with more than $6 \%$ of patients experiencing this problem according to a otolaryngology report ${ }^{16}$.

The etiology of transient hypocalcaemia after thyroidectomy is still controversial. Though direct trauma to the parathyroid glands, devascularization or inadvertent excision of the parathyroid glands can impose significant hypocalcaemia, review of recent literatures suggested it to be multifactorial. Some have suggested that nonspecific haemodilution associated with the stress of surgery is responsible ${ }^{17}$. The non-capsular dissection technique may be another cause for the high incidence of hypoparathyroidism, as the parathyroid gland is vulnerable to devascularization or inadvertent removal with the thyroid gland during such a procedure. The fact that hypoparathyroidism did not occur in any case undergoing near total thyroidectomy for toxic goitre, supports the success of capsular dissection to reduce this complication ${ }^{18}$.

Others stated that transient hypocalcaemia following subtotal thyroidectomy is due to a reduction in the renal tubular reabsorption of calcium $^{19}$. The cause of transient hypocalcaemia after surgery is not clearly understood. It may be attributable to temporary hypoparathyroidism caused by reversible ischemia to the parathyroid glands, hypothermia to the glands, or release of endothelin-1. Endothelin-1 is an acute-phase reactant known to suppress PTH production. PTH increases serum calcium levels by causing bone resorption, increasing renal absorption of calcium and stimulating the synthesis of the biologically active form of vitamin D (1,25-dihydroxy vitamin D) which increase serum calcium level by means of a number of mechanisms, including increasing the intestinal absorption of calcium ${ }^{15}$.

The key to parathyroid preservation is to identify the parathyroids and preserve their blood supply by ligation all vessels distal to them or to ligate the vessels as close as possible. But the number of parathyroid glands preserved in situ did not help predict the duration of post-surgical calcium treatment, nor the final outcome of hypocalcaemia ${ }^{17}$. Furthermore, devascularized gland should be removed, cut into 1 to $2 \mathrm{~mm}$ pieces and reimplanted into a pocket created in the sternocleidomastoid muscle or strap muscle. The location may be marked with a permanent suture or a metallic hemoclip for easier identification in any future surgeries ${ }^{18}$.

In this series transient paralysis of RLN occurred in 2 patients $(2 \%)$ and showed post-operative voice change which recovered in 3 weeks to 3 months. Both of them were carcinoma patients and bilateral procedures were done. Among 38 cancer patients 36 were done bilateral procedures and in 4 cases not possible to identification of RLN at the time of operation. Loss of function can be caused by transection, ligation, traction, contusion, crush, diathermy bum or even a compromised blood supply. The consequence is vocal cord paresis or paralysis. Unilateral paralysis results in hoarseness and worsening voice. Bilateral vocal cord palsy causes partial airway obstruction leading to stridor, respiratory distress or both. Transient paralysis may result from pressure on the nerve by clot or by edema in which case recovery is anticipated. In this study there was not found any patient of permanent paralysis of RLN.

Recurrent laryngeal nerve palsy is the most serious complication in thyroid surgery, resulting in significant impairment of the quality of life and having a negative impact on job performance. The incidence of RLNP varies from $0.0 \%$ to $4.0 \%$ and has been related to the extent of thyroidectomy, the presence of Graves' disease, thyroid carcinoma and the need for reoperation. Karamanakos et $\mathrm{al}^{10}$ in his study found that the transient RLNP occurred in $34(1.6 \%)$ patients and permanent in $19(0.9 \%)$ patients. 
The exact incidence of RLN injury is unknown. Different studies have reported varying prevalence ranging from $0.0 \%$ to $14.0 \%$ cases ${ }^{19}$. This difference in complication rates reflects variation in surgical expertise, nature of operation, number of surgeries performed at that particular centre. Intra operative neuro-monitoring with the purpose of identification of the recurrent laryngeal nerve is safe and reliable methods. But this facility is not available in all centres. In long term after thyroid surgery 85 patients were followed up to 6 months and 15 patients did not attend in subsequent follow up. There was no death in our series and acceptable morbidity under the prevailing circumstances.

The overall major postoperative complications rate in this study was $16.0 \%$ and no mortality was reported; however, the overall recent postoperative complications after thyroid in Pakistan rate was $10.7 \%$ cases $^{17}$. Majority of these complications were associated with total thyroidectomy, male gender, and in patients with age more than 30 years ${ }^{3}$. In comparison to this, another recent international study reported nearly $0 \%$ mortality rate and less than $3 \%$ complication rate ${ }^{19}$.

Limitations of this study include a small sample size within a short period of time. The duration of this study was about two years, so samples wear not adequate; if the study period would have been longer, adequate sample size could have been achieved. This study was done in only one institute which in another limitation in context of comparison with outcome of other institutes. Intra operative neuro-monitoring facility is not available in our centre which is safe and reliable methods for identification of the recurrent laryngeal nerve. Also, we were unable to obtain data on the experience of the different surgeons performing thyroidectomy in this study. Most experts feel that the experience of the surgeon is one of the most important factors in the avoidance of postoperative complications.

\section{Conclusion}

There has been a significant reduction in the incidence of complications and mortality in thyroid surgery since the beginning of the 20th century, probably due to safer general anaesthesia, better antisepsis and the development of fine haemostatic instruments. This type of study should be carried out by a single surgeon or same level trained and experienced different surgeons. A sound knowledge of regional anatomy, proper evaluation, operation in a bloodless field by adequate haemostasis to minimize damage of the individual structures and combined with an unhurried meticulous dissection with intra operative identification of the structures are essential for surgeons and is the only way to prevent those major complications.

\section{References}

1. Safioleas M, Stamatakos M, Rompoti N, Mouzopoulos G, lannescu R, Salichou V, Skandalakis P. Complications of thyroid surgery. Chirurgia (Bucur).2006; 101(6): 571-8 1

2. Sabiston DC. Text book of surgery. The thyroid gland. $14^{\text {th }}$ ed. Philadlphia, W.B. Saunders company. 1991. pp 556-97

3. Aziz MM, Khan MAW, Islam S. Endoscopic total thyroidectomy: Report of two cases. J Bangladesh Coll Phys Surg 2008;26(51):46-49

4. Khanzada TW, Samad A, Memon W, Kumar B. Post thyroidectomy complications: The Hyderabad Experience. J Ayub Med Coll Abbottabad 2010; 22(1)

5. Chieh CT, Jeng LB, Lin JD, Chen ME Reoerative thyroid surgery. World J Surg 1997;21: 644-647

6. Leigh D, Guinea Al, Reeve TS. Total thyroidectomy for bilateral multinodular goitre. Arch Surg. 1999;134: 1389-1393

7. Williams NS, Bulstrode CJK, O'Connell PR. Baily and Love's, Short practice of surgery. $25^{\mathrm{h}}$ ed. London, Hodder Arnold, 2008, pp 771806

8. Reeve T, Thonpson NW. Complications of thyroid surgery: how to avoid them, how to manage them and observations on their possible effects on the whole patient. World J Surg. 2000; 24 (8): 971-5

9. Majid MA, Siddique MI. Major post-operative complications of thyroid surgery: preventable or not; Bangladesh Med Res Counc Bull 2008; 34: 99-103

10. Karamanakos SN, Markou KB, Panagopoulos K, Karavias D, Vagianos CE, Scopa CD, Liava A, Vagenas K. Complications and risk factors related to the extent of surgery in thyroidectomy. Results from 2,043 procedures; Hormons 2010, 9(4):318-325

11. Chow TL, Chu W, Lim BH, Kwok SPY. Outcomes and complications of thyroid surgery: retrospective study; HKMJ 2001; 7: 261-5

12. Burge MR, Zeise TM, Johnsen MW, Conway MJ, Qualls CR. Risk of complication following thyroidectomy; J Gen Intern Med. Jan1998; 13(1):24-31

13. Debry C, Renou G, Fingerhut A. Drainage after thyroid surgery: A prospective randomized study. J Laryngol Otol. 1999; 113: 49-51

14. Glinoer D, Andry G, Chantrain G, Samil N. Clinical aspects of early and late hypocalcaemia after thyroid surgery. Eur $\mathbf{J}$ Surg Oncol. 2000; 26: 571-77

15. Demeester-Mirkine N, Hooghe L, De Maertelaer VGJ. Hypocalcaemia after thyroidectomy. Arch Surg. 1992; 127: 854-5 8

16. Percival RC, Hargreaves AW, Kanis JA. The mechanism of hypocalcaemia following thyroidectomy. Acta Endocrinol. 1985; 109: 220-26

17. Sharma PK, Barr U. Complications of Thyroid Surgery; Otolaryngol Head Neck Surg. Feb 19, 2010

18. Tresallet C, Chigot JP, Menegaux F. How to prevent recurrent laryngeal nerve palsy during thyroid surgery. Ann Chir 2006; 131:149-53

19. Lombardi CP, Raffaelli M, De Crea C, Traini E, Oraganao L, Sollazzi L et al. Complications in thyroid surgery. Minerva Chir 2007; 62: 395-408 